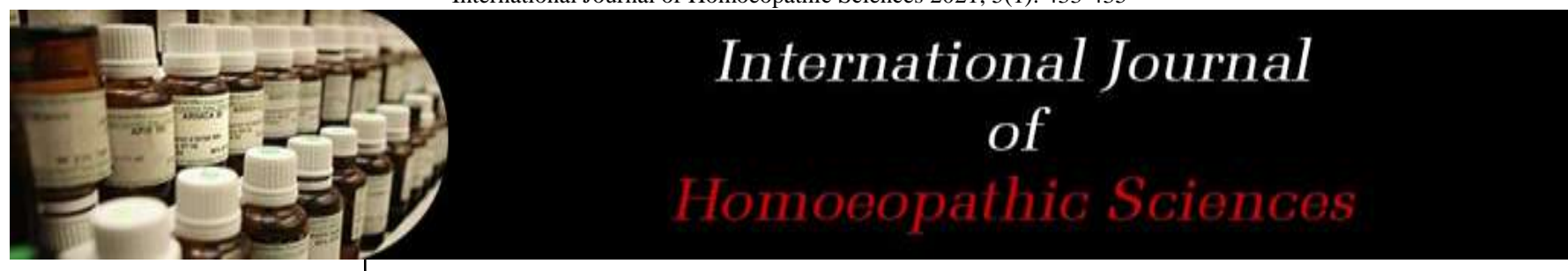

E-ISSN: $2616-4493$ P-ISSN: 2616-4485 www.homoeopathicjournal.com IJHS 2021; 5(1): 433-435 Received: 22-12-2020 Accepted: 26-01-2021

Dr. Tummala Aarathi Reddy Assistant Professor, Department of OBG, MNR Homoeopathic Medical College Sangareddy, Telangana, India

Corresponding Author: Dr. Tummala Aarathi Reddy Assistant Professor, Department of OBG, MNR Homoeopathic Medical College Sangareddy, Telangana, India

\section{ADHD during COVID-19 and homoeopathic management}

\author{
Dr. Tummala Aarathi Reddy \\ DOI: $\underline{\text { https://doi.org/10.33545/26164485.2021.v5.i1g.349 }}$
}

\begin{abstract}
Attention deficit disorder is a common disorder mostly seen in childhood. Children with ADHD may find difficulty in paying attention, controlling their impulsive behavior, hyperactive. During this pandemic situation Children are at home due to the lockdown and was not allowed out even for some amount of time as the schools are closed and even play centres, parks and moving out was not allowed. This closed environment inside a closed house with tight and forcible schedule, which is restricting the children had brought a great increase in cases of ADHD. Objective is to guide that necessity of Orientation classes for parents and need of usage of homoeopathic medicines on treating ADHD.
\end{abstract}

Keywords: ADHD, COVID-19, hyperactivity, boys, children

\section{Introduction}

Attention deficit disorder is a Neurodevelopmental disorder which is distinguished by the symptoms of inattention, hyperactivity, \& impulsivity that are in relation to the developmental level and pervasive across settings and over time, often persisting from childhood into adulthood. The prevalence of ADHD was found to be $7.19 \%$ (95\% CI 5.599.19) for studies conducted in a community-based setting and it was $8.74 \%$ (95\% CI 5.66$13.27 \%$ ). Most of the children are being detected at homes or in Pre- primary schools. Five percent of children worldwide shows ADHD symptoms. Boys are more commonly detected to be Hyperactive when compared with Girls. Primary school children in comparison with Adolscents. In general these Attention deficit/hyperactivity disorder can be managed by consistent schedule and clear guidelines for daily tasks.

But since mid-March 2020, we should agree that neither a consistent schedule nor clear guidelines are missing in everyone's lives. It's really very hard time for ADHD kids to adjust themselves.

Problems faced by ADHD Kids, Parents, Teachers and the dear ones:

When schools were closed in this March 2020 all over in an overnight, ids of all ages found themselves dealing with loss of social and physical activities, including coming up with the introduction of Online classes and forcibly upending their daily life routine.

This would be a difficult situation for every child with Pre-existing ADHD symptoms, Behavioural disorders, Anxiety disorders Autism. Usually Kids with such disorders struggle for adapting themselves to a new situation, where in now it's a great task for children and teachers as well as parents to learn remotely which lack face to face interaction which leads to isolation, boredom, loneliness. Studies revealed that Social isolation is especially harmful for individuals with ADHD, as ADHD usually occurs with other mental health conditions, including anxiety and depression. According to National Sleep Foundation, low quality sleep can exacerbate ADHD symptoms in children.

\section{Clinical Features \\ 2.1 Forgetfulness}

They usually forget their regular routine works like homework, they also lose their toys or things.

\subsection{Self focussed Behaviour}

These children are unable to recognize others needs and desires

\subsection{Interrupting}

These children interrupt others' conversations while they are talking or when they are not part of that game. 


\subsection{Trouble waiting their turn}

These ADHD children cannot wait for their turn either in the classroom or while playing.

\subsection{Emotional Turmoil}

They have temper tantrums like they outburst their anger during an inappropriate times.

\subsection{Fidgeting}

Children doesn't sit at one place they keep wandering all the time. When they are forced to sit they try to run, fidget.

\subsection{Problems playing quietly}

They cant play quietly neither engage themselves in leisure activities.

\subsection{Unfinished tasks}

They lack in concentration and fail to finish the tasks given to them, they switch on to other works without finishing the firstone.

\subsection{Lack of focus}

They lack in paying attention.

\subsection{Commits mistakes}

As they lack in focussing in things they require proper planning and executing them in an order which usually fails due to laziness, lack of intelligence.

\subsection{Day dreaming}

Children usually fail to look into the opposite person and they stare into the space and ignores what is going on around them.

\subsection{Interested in Multiple settings}

They show interest in many thighs but fail to concentrate and complete one setting.

\section{Homoeopathic Therapeutics}

3.1 Agaricus

Stubborn, Self Willed, Awkward, clumsy, Pressure on spine will cause involuntary laughter, convulsions after being scolded, sings talks, but does not answer, Loquacity.

\subsection{Abrotanum}

Child is ill natured, peevish, very violent, wants to do any cruel activity, irritable, depressed.

\subsection{Anacardium}

Child is confused and imagines as if there are two wills child imagines devil is speaking in lear and angel speaking in other, cruel.

\subsection{Aurum met}

Indicated in children who act more than their age, seeks affection, but dont know how to express.

\subsection{Baryata carb}

Timid, fearful, self-limitation, fear of making mistake, teachers pet, immature.

\subsection{Baryta Iodatum}

Irritable, hurriedness, restless, nervous.

\subsection{Belladonna}

Stands for violent attacks, suddenness of onset, Biting, striking, tearing mania. Spots on face of other persons, Cruelty towards animals, people, desire to break things, They are very much excited.

\subsection{Calcarea carb}

Unsafe, afraid of robbers, dogs, heights, cautious, stubborn, hesitating.

\subsection{Calcarea Phos}

Frustrated, Dissatisfied, peevish, restless, shy, fearful, child likes to travel.

\subsection{Carcinosin}

Indicated for those who are timid, unhappy, worried, and obstinate, sensitive, craves or dislike salt, milk, eggs, fat meat.

\subsection{Chamomilla}

Children are sensitive, peevish, irritable, impatient, intolerable quarrelsome, does not concentrate, ugly behavior, interrupting.

\subsection{Hyoscyamus Niger}

Quarrelsome, desire to bite, strike, scold.

\subsection{Coffea cruda}

Nervous excitement, Fainting from sudden emotions, Hysteria, nervousness, weeping, child talks to mother very rapidly with eyes, red face, cannot go to sleep, excitability, fear.

\subsection{Hyoscyamus}

Talking, passive delirium, imaginations, talks during sleep, fear of water, talks hastily.

\subsection{Lachesis}

Child is expressive, passionate, outgoing, creative, vital, lively, constantly overflowing with ideas,doesnt stick to one task, crawls on floors, hides, spits on others, Passionate.

\subsection{Lycopodium}

Child has a lot of inferiority complex, egoism, arrogant, domineering, lack of discipline, irritable, peevish, easily angered, can't accept opposing or any contradiction what the child does.

\subsection{Lac caninum}

Forgetful, Finds difficulty in understanding things, absentminded, very restless, confused, speaks lies.

\subsection{Medorrhinum}

Impulsive child, rude, sad, weeps, mean cruel, abrupt.

\subsection{Nat mur}

Weeping alternates with laughing, Indicated in children who act like adults, display extreme watchfulness, sits in mothers laps, very untidy, craves salt, worsened by sun.

\subsection{Nat sulph}

Remedy indicated for depression, suicidal, anxiety 


\subsection{Nux moschata}

Children can be perfect child-cooperating with parents, sharing, doing chores, going to bed.

\subsection{Platina}

Indicated for children who are insecure, lack of confidence, they have strong feelings of anger, hopeless

\subsection{Stramonium}

Has many emotions which leads to violence which is out of control, wakes up with fright, strong fear during night, likes to sleep with parents, destructive.

\subsection{Tarentula}

Sudden change of mood, rolls on ground from side to side, excited, restless, impatient, selfish, destructive, throws things away with whole hatred.

\subsection{Tuberculinum}

Hyperactive, restless, compulsive, throws things at anyone even without cause, physically and mentally very sensitive, dissatisfied, always wants achange, wants to travel.

\section{How to overcome ADHD symptoms during pandemic 4.1 Create a daily routine}

Which includes scheduling the time for work, homework, physical activity, relaxation.

\subsection{Maintain a calm environment}

Children learn much better in a quiet and neat environment.

\subsection{Inculcate Habit of Exercise}

Regular exercise improves the impulsive nature and attentiveness.

\subsection{Digital Socialisation}

\section{Conclusion}

COVID-19 pandemic this word itself brings attentive environment, adding to which ADHD children, their parents, teachers and caretakers maybe facing hard situation. during this ADHD symptoms may be triggered which brings changes in health conditions, Practising preventive measures creating a routine and taking homoeopathic medicines as per the respective physicians advice with the help of individualization of child, will help child to overcome out of this situation in a holistic way.

\section{References}

1. Joel Nigg. Department of Psychiatry, Oregon Health \& Science University, Portland, Oregon, United States; Department of Psychiatry, Oregon Health \& Science University, 3181 Sam Jackson Park Rd, Portland OR 97239, United States. ude.usho@jggin Clin Psychol Rev. Author manuscript; PMC 2015, 10. Available from https://www.ncbi.nlm.nih.gov/pmc/articles/PMC43224 30 on 3 pm on 3.3.2021

2. American Psychiatric Association. Diagnostic And statistical manual of mental disorders. BMC Med 2013;17:133-7.

3. https://www.thelancet.com/journals/lanchi/article/piis23 52-4642\%2820\%2930110-3

4. Parthasarathy A. IAP Textbook of Paediatrics. Jaypee brothers, Medical Publishers Pvt Limited;2019 Feb 4

5. Ghai OP. Essential paediatrics. CBS Publishers and distributors Pvt limited 2010.

6. Phatak SR. Materia Medica of homoeopathic medicines. B. Jain Publishers 2002.

7. Allen HC. Keynotes and characteristics with comparisons of some of the leading remedies of Materia Medica with Bowel Nosodes. B.Jain Publishers 2002.

8. https://www.medicalnewsoday.com/articles/adhdandcovid-19

9. Clarke JH. A dictionary of practical materia medica. homoeopathic publishing company 1902.

10. Boericke W. Pocket Manual of Homoeopathic Materia medica Repertory B.Jain publishers 2002.

11. Dr. Choudhari NM. A Study on Materia Medica. Revised and augmented edition, B.Jain publishers (P) LTD, New Delhi 2001.

12. Robin Murphy. Lotus Materia Medica.3RD Edition: B. Jain Publishers (P) LTD, New Delhi 2010.

13. Lewis Mehl-Madrona. Ph.D. Associate Professor of Family Medicine and Psychiatry Department of Family Medicine West Winds Primary Health Centre University of Saskatchewan College of Medicine3311 Fairmont Drive Saskatoon, SK S7M 3Y5 Canada. Available from https://www.healingarts.org/children/ADHD/homoeopathy.htm\#Alphabetic al on 3.15pm on 3.3.2021.

14. Allen HC. The Materia Medica of the Nosodes with Provings of X- Ray. B.Jain Publishers 2013.

15. Kent JT. Homoeopathic Materia Medica Bjain Publishers 2002. 